

\title{
La tecnología confesional, un mecanismo oculto pero presente en los procesos de formación de sujetos
}

\section{María Clara Méndez Álvarez}

\begin{abstract}
Resumen
En el presente artículo se pretende mostrar las similitudes y vínculos entre dos tecnologías orientadas a la configuración de sujetos: la tecnología confesional y la tecnología puesta en juego en la primera parte de un proceso pedagógico concreto nombrado como proceso de curación. Al realizar esta vinculación se evidencia un modo de subjetivación que puede ser común a muchos procesos pedagógicos, el cual representa un obstáculo para la singularización de las subjetividades de los estudiantes.
\end{abstract}

\section{Palabras clave}

Prácticas de sí, experiencia de sí, tecnología, tecnología confesional, subjetividad. 


\section{CONFESSIONAL TECHNOLOGY, A HIDDEN MECHANISM NEVERTHELESS PRESENT IN THE FORMATION PROCESSES OF SUBJECTS}

\begin{abstract}
The following paper aims at presenting the links and similarities between two technologies developed for the configuration of subjects: the confessional technology and the technology acting in the first part of a concrete pedagogic process named "healing process". By stating this link, I want to shed light on a subjectification mode that may be common to many pedagogic processes, a mode which is in fact an obstacle for the singularization of the students' subjectivities.
\end{abstract}

\section{Keywords}

Practice of the self, experience of the self, technology, confessional technology, subjectivity.

\section{A TECNOLOGIA CONFESSIONAL, UM MECANISMO OCULTO, MAS PRESENTE NOS PROCESSOS DE FORMAÇÃO DE SUJEITOS}

\section{Resumo}

No presente artigo desejo mostrar as similitudes entre duas tecnologias orientadas à configuração de sujeitos: a tecnologia confessional, e a tecnologia posta em jogo na primeira parte dum processo pedagógico concreto nomeado como "processo curativo". Ao realizar este vinculo pretendo deixar em evidencia um modo de subjetivação que pode ser comum a muitos processos pedagógicos, modo, que significa um obstáculo para a singularização das subjetividades dos estudantes.

\section{Palavras Chave}

Práticas de si mesmo, experiências de si mesmo, tecnologia, tecnologia confessional, subjetividade.

\section{Introducción}

Este artículo expone algunas de las ideas que resultaron del trabajo de grado "Las prácticas de sí en el dispositivo 'encuadre de mujeres': mecanismos para dirigir o herramientas para la creación experimental" ${ }^{\prime 1}$ que tiene como temática central las prácticas de sí. Con este término, acuñado por Foucault, se hace referencia a las acciones que le permiten al sujeto reflexionar sobre sí con miras a transformarse o formarse según ciertos fines. Las narraciones verbales, los escritos autobiográficos y la elaboración de autorretratos son algunos ejemplos que caben dentro de este concepto. Estas acciones se nombran como prácticas porque están orientadas a configurar algo -en este caso la experiencia de sí del sujeto- y por qué se realizan bajo ciertas reglas o "formas de racionalidad que organizan las maneras de hacer" (Foucault, citado por Castro, 2004, p. 426).

Este artículo está orientado a relacionar dos conjuntos concretos de prácticas: el primero de ellos tomado de una experiencia pedagógica, y el segundo proveniente de un acercamiento al pensamiento y producción teórica del filósofo Michel Foucault. Dicha relación muestra cómo ese primer conjunto de acciones abordado se caracteriza por articularse y funcionar de la misma manera que el segundo, lo cual conduce a los sujetos a encarnar una idea sobre sí que no necesariamente aceptaban en primera instancia. De esta forma, se busca llamar la atención de docentes, estudiantes y académicos interesados en las experiencias educativas, sobre la necesidad de mirar críticamente las prácticas de sí que se ponen en juego en dichas experiencias, con el fin de garantizar que las reflexiones que sobre sí realicen los estudiantes se configuren de manera autónoma y no direccionada.

Pero antes de entrar en materia, es pertinente aclarar que, de aquí en adelante, los conjuntos de prácticas que se han mencionado serán entendidos como tecnologías, ya que estos configuran una estructura particular y en la que cada práctica se ubica de tal forma que asegura la configuración de un sujeto específico con unas características determinadas. Esta visión de las tecnologías está anclada en las acepciones que dos lectores de Foucault realizan sobre dicho concepto. La primera es la acepción dada por Castro (2004), quien concibe la tecnología como una estructura compuesta de medios

1 Este trabajo fue un proceso de indagación que buscó suscitar reflexiones sobre el sujeto, específicamente sobre aquellas acciones que condicionan la comprensión que este tiene de sí en una experiencia pedagógica concreta nombrada como encuadre de mujeres. Para tal fin se tuvo en cuenta la pregunta: ¿A través de qué prácticas, cuatro asistentes al proceso de-formación nombrado "encuadre de mujeres", generan experiencias de sí? Se buscó identificar y caracterizar dichas prácticas para saber qué papel cumplieron en la construcción del ser de las participantes, al igual que para saber si estas facilitaban la singularización de las subjetividades. 
y fines para el sujeto, que sometida a reflexión se perfecciona a lo largo del tiempo. La segunda es propuesta por Rose (2003) quien define el concepto como "cualquier montaje estructurado por una racionalidad práctica regida por una meta más o menos consciente" (p. 221).

\section{Dos tecnologías aparentemente distantes}

Una vez introducidos en la temática se describe cada tecnología para aclarar las prácticas que las conforman y sus características más significativas, lo cual permitirá su vinculación. La primera tecnología, para este caso, se denominó diagnóstica.

\section{La tecnología diagnóstica}

Esta se puso en juego en la primera parte de un proceso de formación concreto que se analizó en el trabajo de grado mencionado, y que se denominó proceso de curación. Este tuvo una extensión de cuatro sesiones realizadas por dos profesoras en la Casa de Igualdad de Oportunidades para la las Mujeres (CIO). Allí se buscó que un grupo de mujeres adultas identificaran, develaran y sanaran a través de narraciones verbales y ejercicios artísticos, dolencias y alteraciones que hechos de violencia de género hubiesen dejado en ellas.

Específicamente a través de la tecnología diagnóstica se buscó conocer el estado actual de las mujeres, se quiso saber cuál era su diagnóstico ${ }^{2}$ en el presente. Dicha tecnología, entonces, se compuso de una serie de prácticas orientadas a ayudar a identificar y exponer esos estados. ¿Cuál fue la característica central, dada por profesoras y participantes a estas primeras prácticas? Que las mismas eran medios, puentes útiles para señalar y excretar esos estados, que posiblemente serían de alteración, permitiendo su identificación y posterior tratamiento. De allí que aquí se nombren estas prácticas como de diagnóstico, porque su tarea consistió en ayudar a las participantes a ver y nombrar estados ya existentes, haciéndolos emerger para que fueran reconocidos.

Dentro de este grupo, la primera práctica propuesta a las mujeres fue la revisión de su historia de vida focalizando su atención en un hecho de violencia de género que hubieran padecido. Simultáneamente tuvieron que realizar una segunda acción: seleccionar, dibujar y llevar a la clase un objeto de sanación que tuviera algún tipo de relación cercana con el suceso de violencia. ¿Cuál sería la función de este objeto?, contener las dolencias que emergerían a través del relato para contribuir a su

2 Se utiliza la palabra diagnóstico para hacer referencia a los discursos producidos por las mujeres para definir su experiencia de sí. Este uso se hace a partir de la apropiación del sentido que este término tiene en el campo de la psicología, como informes que dan cuenta de los estados de un sujeto acompañados por hipótesis o inferencias de las causas que generan dichos estados. sanación. La última acción consistió en anotar y compartir con el grupo el hecho de violencia identificado, haciendo hincapié en las sensaciones y sentimientos que este había producido.

Después de las dos primeras acciones, y al socializar el hecho con el grupo, cada participante generó una primera narración oral en la que se definió a sí misma como alterada y agredida, pero en un tiempo pasado; es decir, sin identificarse con ese sujeto que describía, afirmando en algunos casos que dicha experiencia había sido dejada de lado. Si bien este hecho se mantuvo en el primer relato, después de que fuera interpretado por las docentes, en el caso de una de las participantes y después de una serie de acciones orientadas a cargar el objeto. En otro caso, el relato dejó de hacer referencia a una experiencia pasada y se mencionó una vivencia presente. Así se logró el objetivo de desentrañar esa alteración latente. Las mujeres por fin encontraban la verdad sobre sí, ese estado escondido que no habían podido identificar y que a través de las prácticas salía a flote.

Antes de dar paso a la descripción de la segunda tecnología, es necesario explicar dos aspectos del conjunto de prácticas en mención, que serán de gran importancia más adelante. El primero de ellos tiene que ver con eso que se denominó aquí acciones orientadas a la carga del objeto. Cuando las participantes realizaron su primer relato, la idea era que el objeto se cargara de esas dolencias y de los recuerdos del sujeto que las había causado; el objeto entonces tendría que generar repulsión al guardar todas esas experiencias. Dado que la dolencia en un primer momento no estaba presente, los objetos no parecieron llenarse de nada, ni ser agresivos.

Ante esta situación se les propuso a las participantes prácticas para llenar de motivos su objeto, es decir acciones que ayudaran a las participantes a escudriñarse a sí mismas de manera más profunda, para que así salieran sus dolencias para cargar el objeto de recuerdos y sensaciones negativas. Dichas acciones consistieron en la realización de recorridos por lugares similares a los del hecho violento, la toma de fotografías a los objetos en esos escenarios y, en algunos casos, la realización de escritos que hablaran sobre estos. Las idea de la imagen fotográfica, o el producto artístico derivado de esas prácticas de carga, consistía en que ellos también eran medios de expresión similares a las palabras, que las complementarían con el fin de hacer visibles los estados ocultos del sujeto.

En cuanto al segundo aspecto, este consistía en enunciar otro rasgo central de la tecnología diagnóstica. Dicho rasgo radicó en que sus prácticas, en particular su ejecución y su modo de comprensión, fueron establecidas y reglamentadas por saberes 
psicológicos. Este hecho sin duda afectó la forma en que las participantes produjeron enunciados sobre sí y se comprendieron.

Ahora bien, ¿a qué se podía deber la aparición de términos psicológicos en la tecnología diagnostica? Según Nikolas Rose (2007), el campo psicológico y sus prácticas terapéuticas han establecido conocimiento positivo -que se puede considerar verídico- sobre problemas que antes no habían sido abordados por la ciencia. Rose habla de problemas como la forma en que el sujeto debe conducir su vida y a sí mismo, abordar sus dificultades y acontecimientos fuertes. Una vez realizada esta acción -al haber producido ideas que podían considerarse verídicas sobre la forma en que el sujeto debe conducirse-, la psicología se constituye como autoridad legitimada para abordar problemas éticos, haciendo que la esta se vea como campo de saber experto en dichas cuestiones. Tales ideas parecieron muy pertinentes, pues justificaron la aparición de términos psicológicos en el proceso. Estos pudieron ser vistos por las profesoras como conceptos claves validados y confiables para ayudar a que las participantes se comprendieran a sí mismas, trabajaran sobre sí e identificaran los que las afectaban.

\section{La tecnología confesional}

La segunda tecnología a la que se hace mención es muy antigua, se trata de la confesión. Esta constituye un sacramento del catolicismo en el cual un sujeto enuncia verbalmente sus culpas a un sacerdote, quien escucha su relato y lo interviene, con el fin de otorgarle la absolución necesaria para su redención. Foucault (1998), en el primer volumen de Historia de la sexualidad, al realizar el estudio sobre las formas en que los sujetos se han configurado, o han sido configurados como sujetos de una sexualidad, dedica un apartado al abordaje de dicha tecnología. A este autor le interesa la confesión, pues afirma que dicho procedimiento se ha constituido, a lo largo del tiempo, en una matriz que rige la producción de discurso verídico sobre el sexo (p. 79).

Según Foucault (1998), la confesión es una forma de reconocer las propias acciones y pensamientos, lo cual garantiza la autentificación de ese sujeto. Entre las características de esta tecnología se encuentra una regla central que condiciona el discurso que sobre sí realizan los sujetos: el requerimiento de enunciarlo todo. En la confesión se pide al sujeto que dé cuenta de sus propias acciones y pensamientos, habiendo un especial interés en aquellos que son difíciles de decir o enunciar. Se piensa que cuando dicho sujeto expone todo lo que le es propio, comienza a emerger la verdad sobre él, la cual posibilita que este pueda ser conocido en profundidad.

¿Cómo se da ese reconocimiento y exposición al que se hace referencia en la tecnología confesional? La técnica confesional se realiza a través de enunciados que no solo revelan la verdad, sino que al mismo tiempo posibilitan su exteriorización liberando a los sujetos de elementos presentes en su interior. $\mathrm{La}$ palabra deviene entonces medio de expresión que "produce en quien la articula modificaciones intrínsecas, lo torna inocente, lo redime, lo purifica, lo descarga de sus fallas, lo libera" (Foucault, 1998, p. 78).

Pero, ¿qué pasa si los sujetos se negaran a hablar? Para la tecnología confesional este hecho es perjudicial, siendo causado por una coerción. Por tanto se incitará a las personas -y ellas mismas se obligarán- a decir todo, a buscar con ahínco hasta hallar lo oculto, o mejor, lo no dicho ante otros, para sacarlo desde el enunciado.

Otra regla de producción que se considera central es, parafraseando a Foucault (1998), el requerimiento de coincidencia, generado por el ritual ${ }^{3}$ de la confesión, entre narrador y sujeto narrado. Quien habla y pronuncia los enunciados, el "yo empírico" en palabras de Castro-Gómez (2010, p. 248), se espera corresponda con el sujeto del enunciado, aquel sobre el que se está hablando.

3 Para Foucault (1992), el ritual es un sistema de restricción y regulación del discurso. En primer lugar, el ritual define las competencias que debe tener el sujeto que habla, su posición y tipos de enunciados a pronunciar. También delimita los gestos y comportamientos que deben acompañar el discurso. Por último, delimita el efecto del enunciado sobre quien lo produce o sobre quien lo recibe. 
En primer lugar, del mismo modo que en la confesión, en la tecnología diagnóstica se solicitaba a las participantes que enunciaran todo, que contaran ese hecho de violencia centrándose en las sensaciones y sentimientos, elementos que sin duda eran difíciles de exponer ante otros. Dicha exposición solicitada se sugirió por su poder revelador de alteraciones latentes, por su poder de hacer emerger el estado real en que se encontraba el sujeto. De este modo la visión de la palabra como medio de excreción es común a ambas tecnologías; así lo evidencia el fragmento en que una de las docentes invita a las participantes a cargar el objeto sanador: "Y ya a partir de que se llenan de esos motivos, lo llamo yo, piénsense un nombre diferente, ahí cuando, cuando uno puede mencionar las cosas es cuando las empieza a superar antes no, ¿¿sí?”. A las prácticas artísticas también se le atribuyeron tales posibilidades de descarga, al mencionarlas como prácticas para desahogarse y poder expresar lo interno.

La ausencia de enunciación, tal como sucede en la confesión, Un último rasgo a mencionar son las condiciones de fuerza o relaciones de poder que intervienen las narraciones realizadas. En la confesión, el discurso pronunciado por el sujeto requiere de otro que lo solicita, interviene e interpreta, a lo cual Foucault (1998) dirá: “[...] no se confiesa sin la presencia al menos virtual del otro que no es simplemente el interlocutor sino la instancia que requiere la confesión [...] la aprecia e interviene" (p. 78). Ese otro es en últimas quien dice, a través de sus interpretaciones, el significado real o verdadero del discurso de quien se confiesa. Según Foucault (1998):

La verdad no reside en el sujeto sólo que, confesando, la sacaría por entero a la luz. Se constituye por partida doble: presente, pero incompleta, ciega ante sí misma dentro del que habla, sólo puede completarse en aquel que la recoge (p. 84).

\section{Los vínculos entre tecnologías}

Con una mirada rápida pareciera no existir una similitud entre estos dos mecanismos; sin embargo, a este punto es posible darse cuenta de los cuatro aspectos comunes que comparten ambas tecnologías y que hacen a la tecnología diagnóstica funcionar de modo muy similar a la confesión. era mal vista y se sancionaba como signo de enfermedad. Así lo demuestra la siguiente afirmación referida a los dolores realizada por una de las docentes: "Cuando uno los esconde es cuando todavía siguen doliendo, por decirlo de alguna forma, ¿`sí?". Quien no hablaba era porque estaba enfermo, porque quería evitar exponer su herida, tal como al pecador le cuesta exponer su pecado.

Un tercer rasgo compartido consistió en la coincidencia entre sujeto narrado y narrador. Ya desde el inicio de la tecnología diagnóstica, al proponer objetos sanadores sin el conocimiento del estado presente de las participantes, las docentes establecieron esta regla para la generación de discursos. Las participantes aceptaron así, la idea de que el diagnóstico pasado necesariamente se correspondería con el diagnóstico presente, hecho que no podía ser comprobado. Como resultado de tal aceptación, las participantes a través de la práctica discursiva trajeron al presente la alteración identificándose con ella.

Las relaciones de poder fueron el último elemento común para ambas técnicas. Cómo se ha podido ver a lo largo de este documento, las primeras narraciones que fueron producidas en la tecnología diagnóstica, derivadas de la revisión de la historia de vida, emergieron en una relación entre participante -aquel sujeto que hablaba sobre sí- y profesoras. Estas últimas solicitaban los diagnósticos, los escuchaban; pero también quienes los interpretaban definiendo su significado y acepciones ${ }^{4}$.

4 Estas interpretaciones se dieron casi de forma exclusiva en el caso de una de las participantes. 


\section{Sobre el origen del vínculo}

¿Cómo pudo estar presente, en un proceso pedagógico que buscaba a través del trabajo realizado por unas mujeres sobre sus sufrimientos, una técnica tan antigua como la confesión? Este hecho se dio por la reglamentación que estableció el saber psicológico sobre las prácticas de la tecnología diagnóstica.

La psicología, que se ha ocupado de generar saberes verídicos sobre asuntos éticos, está llena de técnicas de trabajo para que los sujetos se aborden a sí mismos. Foucault (1998) mostraría cómo dicha ciencia, junto con la medicina, se apropiaría a través de cuatro procedimientos de la práctica confesional, integrándola como técnica privilegiada de producción de verdad.

Al ser el primer conjunto de prácticas de la técnica, sustentada en este gran campo del saber no se podía entonces más que esperar que la tecnología confesional fuera su guía y sustento, ocultando simultáneamente su presencia a través de términos que pareciesen alejados de ella como sanación, catarsis, expresión y trámite.

\section{El peligro de la tecnología confesional}

$¿$ Cuáles son las consecuencias que trajo consigo para las participantes que realizaron las prácticas de la tecnología diagnóstica, el que dicha tecnología funcionará de la misma manera que la confesión? De modo más general, ¿qué consecuencias puede traer para un sujeto abordarse y reflexionar sobre sí a partir de prácticas confesionales? Para decirlo de manera simple, la tecnología confesional a través de sus prácticas produce en los sujetos esas experiencias, esas sensaciones, que pretende ayudar a expresar y hacer emerger. En el caso abordado, todas las acciones llevaron a que las participantes se configuraran como alteradas, revivieran dolores y se configuraran a partir de los mismos.

Si bien no es el objetivo del presente artículo argumentar en profundidad las razones por las cuales las prácticas confesionales producen aquello que pretenden evidenciar, sí se expone de forma sucinta algunas ideas claves que, aterrizadas al caso concreto expuesto, ayudan a sustentar esta idea.
En primer lugar al asignar a los enunciados una función exclusivamente expresiva se niega su capacidad productiva de dos formas: uno, asignándole un papel de mediador, de forma vacía que se llena de significado y cuyo sentido depende exclusivamente del sujeto que lo enuncia, y dos, estableciendo la idea de la existencia de una serie de sustancias ocultas caóticas, peligrosas presentes en el sujeto que, al estar escondidas, no son visibles ni para el propio portador ni para los demás sujetos.

Con respecto a la visión del lenguaje como medio, es posible afirmar que es equívoca, pues el lenguaje precede al sujeto generando su propia sustancia, e implica, como afirma Foucault (1992), una violencia hecha a las cosas, una práctica impuesta a la realidad. Así, cuando las participantes se dijeron angustiadas, con rabia e ira, fueron configuradas por esas palabras, se construyeron a partir de ellas.

Con los productos artísticos sucedió algo similar, tanto el objeto como la imagen fotográfica no fueron contenedores pasivos en los cuales las participantes depositaban sus dolencias. Antes bien, actuaron como huéspedes, portadores de agentes, de esos sujetos que ejercieron la violencia, quienes lejos de estar neutralizados, se encontraban latentes y listos para dañar. ¿De dónde procedían esos agentes de dolor? Lejos de ser las participantes los cuerpos de procedencia de estos, los recorridos, la toma de fotografías y la realización de relatos escritos convocaron dichos agentes teniendo una gran cuota de participación en su aparición y presencia. Esto debido a que todos ellos configuraron una forma artística ${ }^{5}$ de contagio que, al reconstruir en detalle el evento de violencia, convocó los recuerdos dolorosos que habían afectado a las participantes. Esos recuerdos de los sucesos y del sujeto violento, al entrar en contacto con cada una de las mujeres, produjeron que su experiencia alterada se hiciera presente.

La creencia de permanencia de sustancias ocultas dentro del sujeto también puede ser cuestionada, por dos motivos. El primero, porque parte del desconocimiento de la historia de vida de las participantes y más que de su historia, de las prácticas de curación, que en ésta; dichas participantes se aplicaron a sí mismas con el fin de dejar en el pasado los dolores producidos por la violencia. María, una de las mujeres, enunció dentro de su relato una de esas prácticas curativas, pero la misma no fue tenida en cuenta durante el diagnóstico.

Un segundo argumento consiste en que a través de esta creencia se resta de nuevo el papel productivo de los enunciados, imponiendo ahora la idea de una experiencia originaria (Foucault, 1992, p. 40). Experiencia de alteración que, parafraseando a Foucault, murmura un sentido que el lenguaje

5 Al hablar de forma hay una referencia al pensamiento de Bourriaud (2008), para quien dicho concepto es una unidad o amalgama compuesta de hechos heterogéneos que se interrelacionan configurando un mundo. Las diversas prácticas artísticas puestas en juego en la tecnología diagnóstica se articularon y juntas generaron una unidad, así se constituyeron en universo base de encuentros y modelador de universos posibles, parafraseando a Bourriaud (2008). 
únicamente debe hacer brotar. Las consecuencias de la creencia en sustancias ocultas, fue llevar a las participantes a que se sintieran obligadas a hablar, a decir todo sobre sí, a mencionar lo que no querían. Al hacerlo, al contar todo en detalle, las situaciones, los sentimientos, los dolores, al cargar los objetos, ellas se produjeron, se constituyeron a sí mismas enfermas por la acción de todos estos elementos en su propia forma de sujeto.

Si ver al lenguaje y a los productos artísticos como medio de expresión contribuyó en gran medida a enmascarar su carácter productivo y a propiciar que las participantes revivieran las alteraciones que habían padecido, las relaciones de poder que condicionaron las narraciones también fueron pieza clave en esta reactivación de las dolencias.

Para Foucault (1998), en la tecnología confesional el sujeto que recibe la confesión tiene una función hermenéutica; es decir, su rol consiste principalmente en interpretar el discurso de quien habla, desentrañar la verdad que las palabras han hecho emerger sobre él. En el caso que se abordó, las profesoras asumieron ese papel de sujetos interpretantes cuando realizaron comentarios sobre la primera narración de una de las participantes. $\mathrm{Al}$ realizar su intervención no solo sugirieron a dicha participante las acciones que debía tomar sobre sí, sino que le dijeron en qué estado se encontraba y la realidad que ocultaba.

Los enunciados de las profesoras no tendrían un mayor impacto, no adquirirían un poder constitutivo si no estuvieran generados dentro de una tecnología que les asigna una función de establecimiento de la verdad sobre el sujeto. Ejerciendo esta función entonces, comentarios que podían estar no sustentados, fueron para la participante que los escuchaba una interpretación verídica, que haría que la misma se pensara a sí, no solo como un sujeto cuyas dolencias aún estaban presentes; sino como un sujeto que había ocultado dicha alteración dentro de sí, negándose a verla y dejándola sin tratamiento.

\section{A modo de cierre}

La tecnología diagnóstica perteneciente al proceso de curación funcionó de la misma manera que el ritual confesional. Este hecho reglamentó la producción de discurso de las participantes al proceso de curación de modo tal que estas se configuraron según aquello que buscaban develar y expresar.

Este hecho es un llamado de atención para toda la comunidad educativa, pues si lo que se busca es que el sujeto singularice su subjetividad ${ }^{6}$, configurándose según sus propias ideas

6 En la obra "Micropolíticas cartografías del deseo", Guattari y Rolnik (2006) afirman aue la subietividad puede ser asumida por los individuos 
y visiones, es necesario que se evite la puesta en marcha de grupos de prácticas que le indiquen a ese sujeto la forma en que debe comprenderse y que lo conduzcan a producirse según experiencias que tal vez haya dejado de lado. Así se debe propiciar el juego experimental con cada práctica, que lleven al sujeto a configurarse de diferentes modos, sin perseguir un fin establecido e impuesto.

La tecnología confesional es más cercana a los procesos pedagógicos de lo que se cree y se enmascara utilizando otros saberes que no le son cercanos, como los saberes psicológicos. En futuras publicaciones se tratará un poco más este vínculo, pues se considera que en procesos pedagógicos establecidos con poblaciones concretas, como aquellas en condición de vulnerabilidad, esta unión podría estar orientando las prácticas, especialmente aquellas que se ligan al arteterapia.

\section{Referencias bibliográficas}

Bourriaud, N. (2008). Estética relacional. Buenos Aires: Adriana Hidalgo Editora.

Castro, E. (2004). El vocabulario de Michel Foucault: un recorrido por sistemas, conceptos y autores. Quilmes, Argentina: Universidad Nacional de Quilmes.

Castro-Gómez, S. (2010). Historia de la gubernamentalidad. Razón de Estado, liberalismo y neoliberalismo en Michel Foucault. Bogotá: Siglo del Hombre Editores.

Guattari, F. y Rolnik, S. (2006). Micropoliticas cartografías del deseo. Madrid: Traficantes de Sueños Editorial.

Rose, N. (2003). Identidad, genealogía, historia. En: S. Hall y P. Du Gay (ed.). Cuestiones de identidad cultural (pp. 214251). Buenos Aries: Amorrortu.

Rose, N. (2007). Terapia y poder: Techné y Ethos. Revista Archipiélago, 29.

Foucault, M. (1998). Historia de la sexualidad 1: La voluntad del saber. México D.F.: Siglo XXI Editores.

Foucault, M. (1992). El orden del discurso. Buenos Aires: Tusquets Editores.

en sus existencias de dos maneras: la primera es de forma pasiva; mientras que la segunda es de forma expresiva y creativa, en donde el individuo se apropia de los componentes de su subjetividad y trabaja sobre ellos produciendo así un proceso de singularización de esta.
María Clara Méndez Álvarez es licenciada en Artes Visuales de la Universidad Pedagógica Nacional, en su trayectoria académica ha centrado sus indagaciones en el sujeto y los mecanismos a través de los cuales define lo que es. Actualmente se desempeña como promotora cultural de Colsubsidio, encargada de realizar procesos pedagógicos con niños y jóvenes en las jornadas complementarias de los municipios aledaños a la cuidad de Bogotá.

makis1692@hotmail.com

Artículo recibido en marzo de 2015 y aceptado en mayo de 2015 